\title{
Bulk Metallic Glasses for Industrial Products
}

\author{
Nobuyuki Nishiyama $^{1}$, Kenji Amiya $^{1}$ and Akihisa Inoue ${ }^{1,2}$ \\ ${ }^{1}$ RIMCOF Tohoku University Laboratory, R\&D Institute of Metals and Composites for Future Industries, Sendai 982-0807, Japan \\ ${ }^{2}$ Institute for Materials Research, Tohoku University, Sendai 980-8577, Japan
}

\begin{abstract}
By use of excellent properties of bulk metallic glasses, some industrial products were practically prepared and their performances were investigated. Ni-based BMG microgear prepared by injection casting exhibits nano-imprintability against the surface roughness of mold. Linear actuator constructed by a set of Fe-based BMG yokes generates relatively large driving force due to the Lorentz force. The newly developed alloy with a nominal atomic composition of $\mathrm{Ti}_{52} \mathrm{Cu}_{23} \mathrm{Ni}_{11} \mathrm{Mo}_{7} \mathrm{Fe}_{7}$ exhibits high yield strength of $1250 \mathrm{MPa}$, high fracture strength of $2740 \mathrm{MPa}$ and large plastic elongation of over $20 \%$. These results for the industrial products made of BMGs are promising for future developments as industrial materials with high performance.
\end{abstract}

(Received November 25, 2003; Accepted January 6, 2004)

Keywords: bulk glass-forming systems, industrial applications, nano-imprintability, Lorentz force, nonequilibrium alloy

\section{Introduction}

Due to global problems of fossil fuel saving, environmental pollution and recycling, materials for industrial parts are now strongly required to have higher performances. In addition, near-net or net forming processes for the parts production become also important on the point of energy saving. In such circumstances, much attention has been focused on bulk metallic glasses (BMGs) because of their unique properties for new industrial materials. It is well known that BMGs exhibit excellent properties such as ultrahigh strength, large elastic elongation, high corrosion resistance, good soft-magnetic properties, surface superflatness and viscous deformability, due to their unique structures of dense and random atomic configurations. At present, many bulk glass-forming systems ${ }^{1)}$ such as La-, Mg-, $\mathrm{Zr}-, \mathrm{Pd}-, \mathrm{Fe}-$, Ni- and Cu-based alloys have been reported and these excellent properties have been also clarified. These finding of new bulk glass-forming systems widely open up the window for applying the BMGs to new industrial products with high performance. This paper intends to introduce new functional and structural applications of BMGs for actual industrial parts. The performances of several products made of BMGs are also discussed in comparison with those of conventional products.

\section{Experimental Procedure}

Ingots with nominal atomic compositions of $\mathrm{Ni}_{53} \mathrm{Nb}_{20^{-}}$ $\mathrm{Ti}_{10} \mathrm{Zr}_{8} \mathrm{Co}_{6} \mathrm{Cu}_{3}{ }^{2)}$ for production of microgear, $\left(\mathrm{Fe}_{0.6} \mathrm{Co}_{0.4}\right)_{72^{-}}$ $\mathrm{Si}_{4} \mathrm{~B}_{20} \mathrm{Nb}_{4}$ for magnetic yoke and $\mathrm{Ti}_{52} \mathrm{Cu}_{23} \mathrm{Ni}_{11} \mathrm{Mo}_{7} \mathrm{Fe}_{7}$ for high strength Ti-based alloy were prepared by arc melting the mixtures of pure elements (above 99.9 mass\% purity) under a purified Ar atmosphere. Ni-based glassy microgears with complicated shapes were prepared by an injection casting method. ${ }^{3,4)}$ Injected speed, pressure and temperature were $3.0 \mathrm{~m} / \mathrm{s}, 30.0 \mathrm{MPa}$ and $1630 \mathrm{~K}$, respectively. Outer shape and surface roughness of the microgear were examined by scanning electron microscopy (SEM) and confocal scanning microscopy (SCM, Lasertec HD-100D). Fe-based glassy plates were prepared by a squeeze casting method. ${ }^{5)}$ After surface polishing and machining, the plates were used for the magnetic yoke of linear actuator. Moving coil type linear actuator was constructed with a permanent magnet, drive circuit and power source. The actuator was driven by rectangular wave of alternating current (AC) with frequencies ranging from 20 to $50 \mathrm{~Hz}$. Cylindrical Ti-based alloy rods with of nonequilibrium crystalline structure were prepared by a conventional $\mathrm{Cu}$-mold casting method. ${ }^{6)}$ The structures of all the prepared samples for the microgears, the magnetic yokes and the high strength Ti-based alloy were examined by X-ray diffractometry (XRD) and transmission electron microscopy (TEM).

\section{Results and Discussion}

\subsection{Microgear for micro motor}

For production of microgear, a Ni-based glass-forming alloy was chosen because of its relatively high GFA, high strength exceeding $3000 \mathrm{MPa}$, good ductility and high corrosion resistance. ${ }^{2,7,8)}$ Figure 1 shows the outer appearance of the microgear prepared by a newly developed injection casting equipment using an electro-discharged machining mold with $5.1 \mu \mathrm{mRy} .{ }^{4)}$ The microgear has a complicated shape consisting of sun-gear with a diameter of $640 \mu \mathrm{m}$ and a module of 0.04 , carrier plate with a diameter of $1.7 \mathrm{~mm}$ and three pins with diameters of $0.3 \mathrm{~mm}$. Dimensional deviation in the diameter of pins between the die and prepared microgear is less than $0.10 \mu \mathrm{m}$. This result suggests that the microgear prepared by injection casting has precise dimension with respect to the cavity dimension of die. As seen in the figure, the outer surface is smooth and neither appreciable ruggedness nor concave due to crystallized shrinkage is seen, indicating the formation of a glassy phase. The microarea XRD pattern of the microgear is also shown in Fig. 1 (inset). The pattern consists only of broad peak and no appreciable sharp peak due to a crystalline phase is seen. Besides, DSC curve of the microgear (not shown here) exhibits the same characteristics as that of the corresponding melt-spun ribbon. These results indicate that the microgear prepared by injection casting is composed only of glassy phase. In addition, the complicated and precise shape of the microgear 


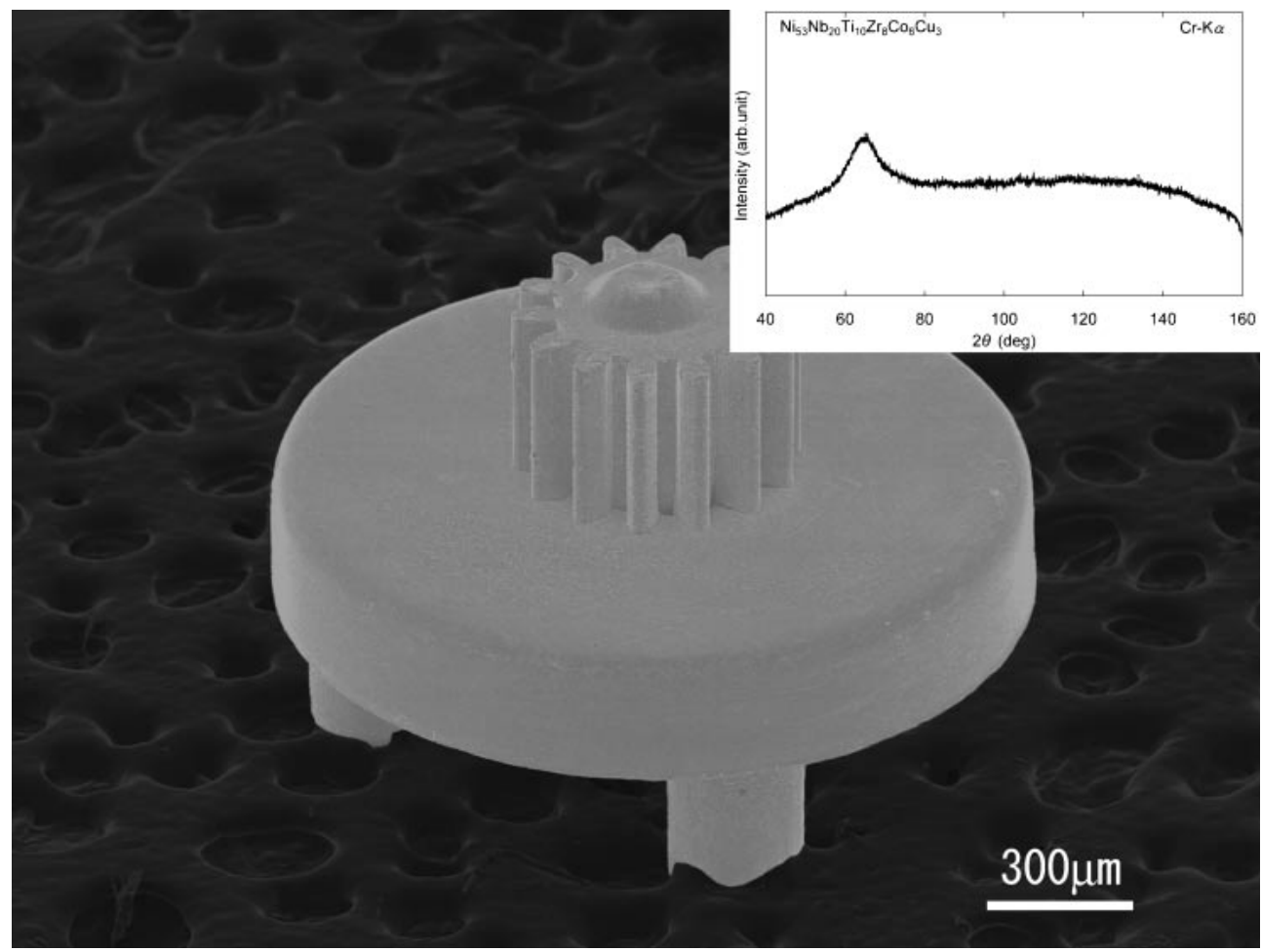

Fig. 1 Outer appearance of the microgear prepared by an injection casting using an electro-discharged machining mold with $5.1 \mu \mathrm{m} R y$. Microarea XRD pattern of the microgear is also shown in the inset figure.

is the evidence of excellent fillability of the Ni-based glassforming alloy.

In order to confirm the advantage of Ni-based metallic glass, fillability and castability were investigated using a Vickers indented mold. Typical depth of Vickers indention was about $6.2 \mu \mathrm{m}$. Conventional Al-based alloy for diecasting (Al-Cu-Si system; ADC12 in JIS) was also investigated for comparison. Figure 2 shows a three-dimensional appearance of imprinted Vickers indention for a) Ni-based metallic glass and b) ADC12. It is clear that the appearance for the ADC12 contains large grooves, and the surface morphology of the imprinted indention for ADC12 is relatively rough. For quantitative analysis, filled areas for the Ni-based metallic glass and ADC12 are evaluated. Ratio of the filled region is evaluated to be $99 \%$ for the Ni-based metallic glass. Taking the measurement error into account, this result indicates that the fillability of Ni-based metallic glass is complete. On the other hand, the ratio for ADC12 is $84 \%$ and the fillability is poor in spite of its relatively smooth surface among the conventional crystalline alloys. Cross sectional profile of imprinted indention for c) Ni-based metallic glass and d) ADC12 is also shown in the figure. One can clearly notice that the profile of ADC 12 contains a concaved groove and a clearance between mold and imprinted sample. For the ADC12, the molten alloy will suddenly loose its fillability due to solidification when touching the mold. As a result, the clearance and the groove remain. On the contrary, the molten alloy for Ni-based MG has the fillability due to undercooling still below its melting temperature. The generated clearance or groove will be eliminated by gradual increasing of viscosity. Consequently, it is important to point out that the fillability of glass-forming alloys is superior to that of conventional crystalline alloys. In other words, the advantage of fillability and imprintability for glass-forming alloys is attributed to its relatively longer period until freezing into solid than conventional crystalline alloys. It is therefore concluded that the metallic glasses are appropriate materials for production of micro-precision parts.

\subsection{Magnetic yoke for linear actuator}

It is well known that conventional $\mathrm{Fe}$ - and Co-based amorphous alloys exhibit good soft magnetic properties, in particular, high saturated magnetic flux density for the former alloys and high permeability with zero saturated magnetostriction for the latter alloys. ${ }^{9)}$ Although these amorphous alloys have been formed in Fe-Si-B, Fe-P-C and Co-Fe-Si-B systems, the production of their amorphous alloys requires high cooling rates exceeding $10^{5} \mathrm{~K} / \mathrm{s}$ and the resulting material thickness is usually limited to less than $50 \mu \mathrm{m} .{ }^{9)}$ Since 1995, Inoue and his colleagues have succeeded in finding a number of Fe-based glass-forming systems. ${ }^{10-14)} \mathrm{By}$ use of these findings, we slightly modified the composition of $\mathrm{Fe}-\mathrm{Si}-\mathrm{B}-\mathrm{Nb}^{15}$ ) system in order to enhance glass-forming ability and ductility. Figure 3 shows I-H loop of glassy ribbons for $\left(\mathrm{Fe}_{0.6} \mathrm{Co}_{0.4}\right)_{72} \mathrm{Si}_{4} \mathrm{~B}_{20} \mathrm{Nb}_{4}$. Saturation magnetization $\left(I_{\mathrm{s}}\right)$ and maximum permeability $\left(\mu_{\max }\right)$ for the $\left(\mathrm{Fe}_{0.6^{-}}\right.$ $\left.\mathrm{Co}_{0.4}\right)_{72} \mathrm{Si}_{4} \mathrm{~B}_{20} \mathrm{Nb}_{4}$ glassy ribbon are $1.15 \mathrm{~T}$ and 73000 , respectively. These values indicate that the alloy has relatively good soft magnetic properties. Using prepared BMG plate as a set of yokes, the trial product of linear actuator was constructed. Figure 4 shows the outer appearance of linear actuator system including power source, AC wave generation circuit, power amplifier and actuator. The actuator is assembled by two pieces of SmCo permanent 

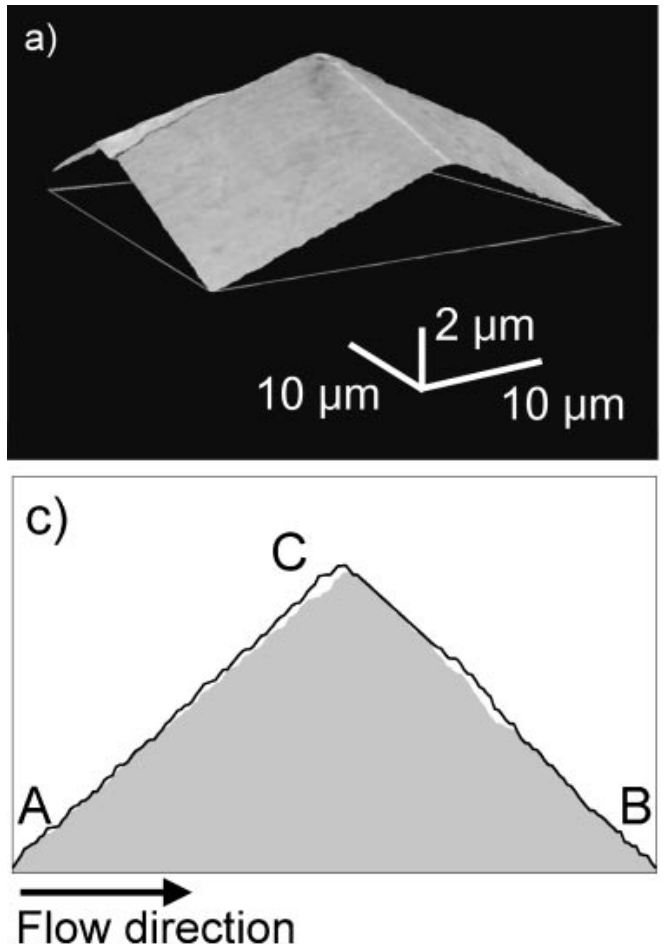
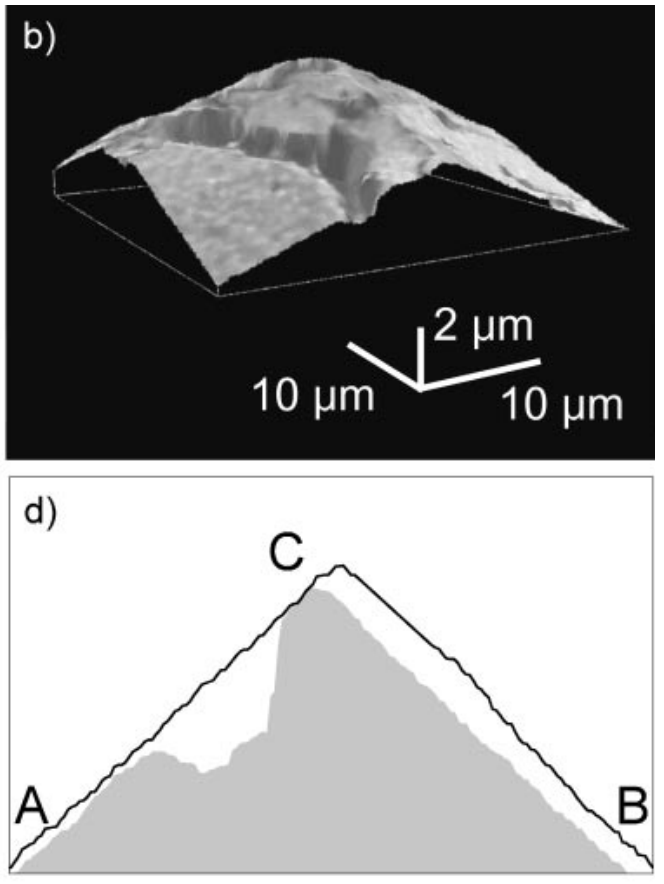

Fig. 2 Three-dimensional appearance of imprinted Vickers indention for a) Ni-based metallic glass and b) ADC12. Cross sectional profile of imprinted indention for c) Ni-based metallic glass and d) ADC12 is also shown in the figure.

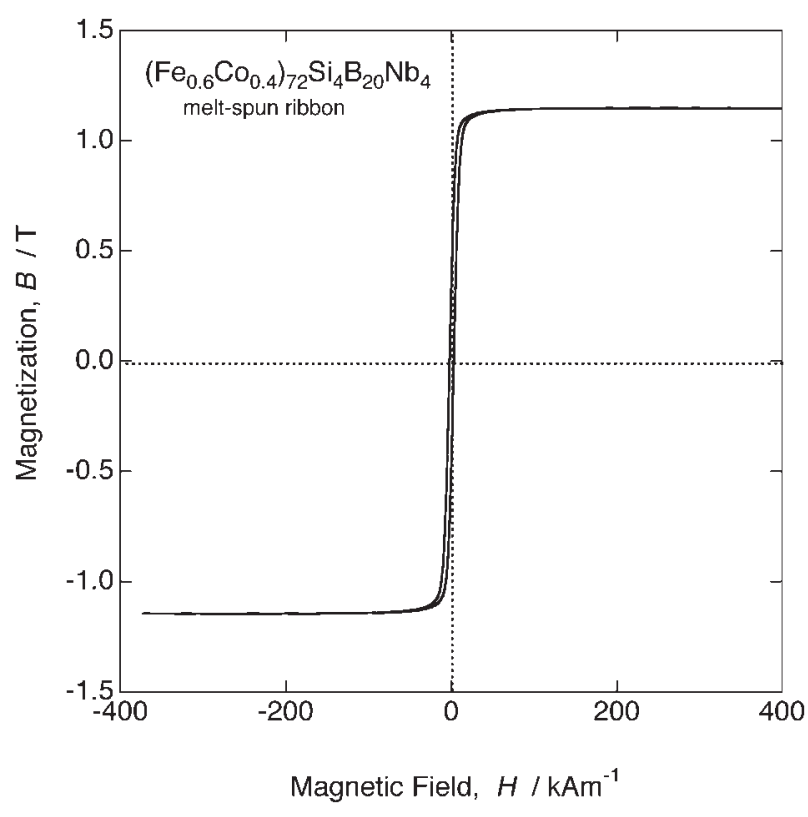

Fig. 3 I-H loop of glassy ribbon for $\left(\mathrm{Fe}_{0.6} \mathrm{Co}_{0.4}\right)_{72} \mathrm{Si}_{4} \mathrm{~B}_{20} \mathrm{Nb}_{4}$.

magnets with width a of $5 \mathrm{~mm}$ and a length of $20 \mathrm{~mm}$, which are sandwiched by a set of magnetic yokes made of Fe-based BMG with a width of $20 \mathrm{~mm}$, a thickness of $1 \mathrm{~mm}$ and a length of $20 \mathrm{~mm}$. The outer shapes magnetic yoke of as-cast, surface polished and machined states are shown in the same figure as an inset. In such magnetic circuit, the voicecoil was inserted into one of yokes. By applying AC, the voicecoil was forced to move alternatively by the Lorentz force. For the linear actuator, the generated driving force $\left(F_{\mathrm{em}}\right)$ is the most important property. Hence, the $F_{\mathrm{em}}$ was evaluated by measuring the amplitude of voicecoil moving. Figure 5 shows the $F_{\text {em }}$ as a function of frequency of applied AC for the linear actuator made of Fe-based BMG yoke. Those for commercial soft magnetic iron and permalloy are also shown for comparison. The $F_{\mathrm{em}}$ for Fe-Co-Si-B-Nb BMG yoke is evaluated to be about $0.4 \mathrm{~N}$, and is independent of applied AC frequency. On the other hand, the $F_{\mathrm{em}}$ for commercial soft magnetic iron and permalloy are evaluated to be 0.6 and $0.2 \mathrm{~N}$, respectively. The $B_{\mathrm{s}}$ for the soft magnetic iron and the permalloy used in the present study are 2.15 and $1.40 \mathrm{~T}$. Besides, the $\mu_{\max }$ for each alloy is 6000 and 30000 , respectively. The value of $F_{\mathrm{em}}$ is not determined only by the value of $B_{\mathrm{s}}$, but it has strong effect upon the value of $F_{\mathrm{em}}$. However, it is important to point out that the yoke made of Fe-based BMG is already saturated due to the generated magnetic flux of permanent magnet in the present construction and the applied AC. ${ }^{15)}$ These results indicate that the construction of actuator and drive circuit is required to improve by optimum designing for BMGs. By use of high permeability of Fe-based BMGs in the high frequency region, fast-driven, precision positioning and large $F_{\text {em }}$ linear actuator can be developed. The results of further investigation will be reported in the near future.

\subsection{Nonequilibrium Ti-based crystalline alloy with high strength and good ductility}

Ti-based BMGs such as Ti-Cu-Ni-Sn ${ }^{16)}$ and Ti-Zr-Cu-Ni$\mathrm{Al}-\mathrm{Si}-\mathrm{B}^{17)}$ are most applicable for the materials of transportation equipment due to their high strength and relatively lightweight. However, there remains difficulty to apply Tibased BMGs for industrial materials. Generally, most of 


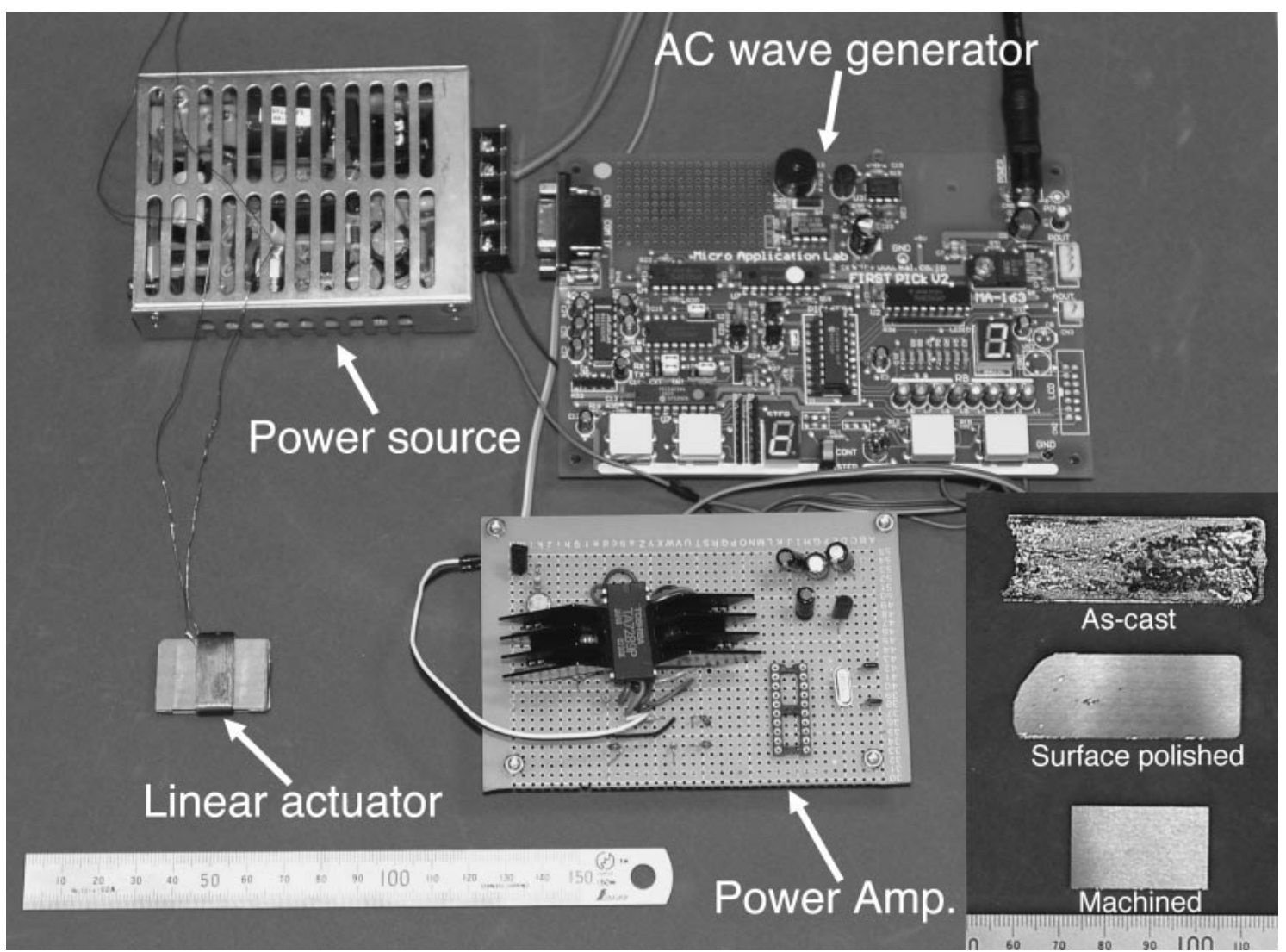

Fig. 4 Outer appearance of linear actuator system including power source, AC wave generation circuit, power amplifier and actuator. Outer shapes magnetic yoke of as-cast, surface polished and machined states are also shown in the inset figure.

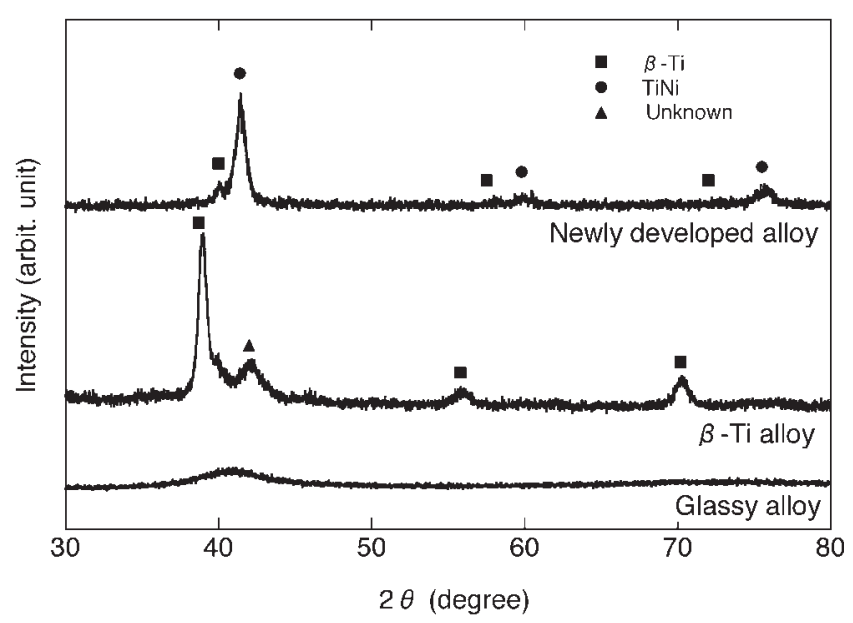

Fig. 5 The $F_{\text {em }}$ as a function of frequency of applied AC for the linear actuator made of Fe-based BMG yoke, those for commercial soft magnetic iron and permalloy are also shown for comparison.

BMGs exhibit linear elastic deformation and then catastrophic fracture in a single axis strain mode. In fact, this elastic deformation behavior has an advantage for the designing allowable stress and factor of safety, but its fracture manner has disadvantages for designing under limit-state, fatigue and impact stresses. To avoid the disadvantages of the BMGs, several attempts have been introduced. For example, adding element $^{18)}$ and embedding reinforcement particle ${ }^{19)}$ or fi- bers $^{20)}$ are employed in order to form glass/crystalline composites. Especially, the methods of in-situ precipitation of nano- or micro-sized dendrites by adding elements for $\mathrm{Zr}^{21)}$ and Ti-based ${ }^{22)}$ BMGs are remarkably achieved to improve their strength and ductility. We tried to find a possibility for improvement in strength and ductility by not only the dendritic $\beta$-phase dispersion into glassy matrix but also mixed intermetallic compounds without glassy phase. As a result, it is found that a cast new alloy with a nominal composition of $\mathrm{Ti}_{52} \mathrm{Cu}_{23} \mathrm{Ni}_{11} \mathrm{Mo}_{7} \mathrm{Fe}_{7}$ exhibits high yield and fracture strength, and large plastic elongation. ${ }^{23)}$ Figure 6 shows XRD profile of the newly developed alloy with a diameter of $3 \mathrm{~mm}$, together with the glassy alloy ${ }^{17)}$ with a diameter of $2 \mathrm{~mm}$, and the $\beta$-Ti alloy ${ }^{22)}$ with a diameter of $3 \mathrm{~mm}$. For the glassy alloy, XRD profile shows only a broad peak revealing a single glassy structure. On the other hand, the $\beta$-Ti alloy and the mixed compound alloy clearly contain several sharp peaks corresponding to the precipitation of crystalline phase. However, crystalline peaks of the developed alloy are slightly different from those of the $\beta$-Ti alloy, indicating that the precipitation phases for the two alloys are different. The peaks appearing for the developed alloy indicate that the alloy is composed of three different phases and could be indexed as bcc structured $\beta$-Ti phase, TiNi compound and unknown phase. Results by scanning electron microscopy (SEM), energy dispersed spectroscopy (EDS) and TEM reveal that these three phases are primary precipitated $\beta$-Ti particles with a chemical composition of 


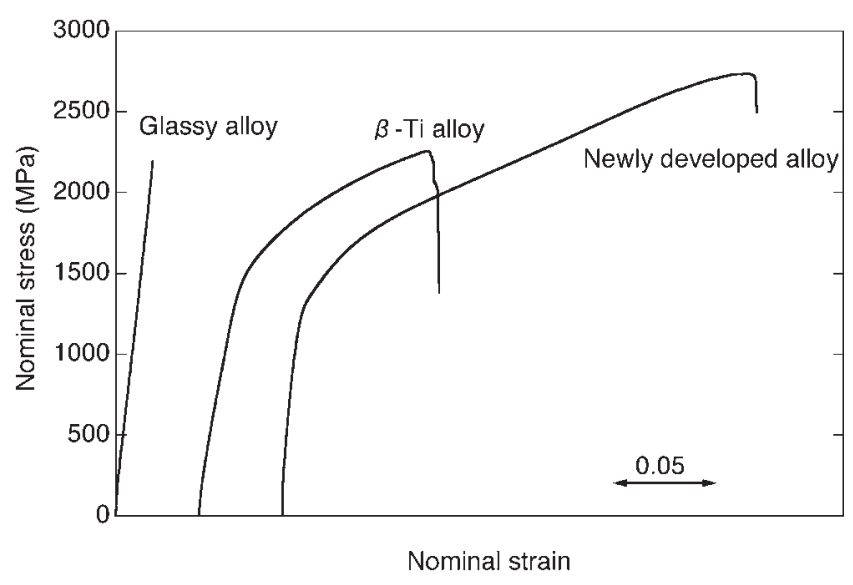

Fig. 6 XRD profile of the newly developed alloy with a diameter of $3 \mathrm{~mm}$, together with the glassy alloy with a diameter of $2 \mathrm{~mm}$ and the $\beta$-Ti alloy with a diameter of $3 \mathrm{~mm}$ are also shown for comparison.

$\mathrm{Ti}_{51} \mathrm{Mo}_{49}$, fine dendrites of TiNi compound and a small amount of residual $\mathrm{Ti}_{2} \mathrm{Cu}^{24)}$ Figure 6 shows the stress-strain (S-S) curve of the developed alloy under compressive stress, together with those of the glassy alloy and the $\beta$-Ti. As shown in the figure, it is seen that the mixed compound alloy exhibits $\sigma_{\mathrm{y}}$ of $1250 \mathrm{MPa}, \sigma_{\mathrm{f}}$ of $2740 \mathrm{MPa}$ and $\varepsilon_{\mathrm{p}}$ of $20 \%$ under compressive stress. In the same condition, the glassy alloy and the $\beta$-Ti alloy were also tested. For the glassy alloy, the $\mathrm{S}-\mathrm{S}$ curve showed a typical BMGs feature, such as high elastic limit and catastrophic fracture. The $\sigma_{\mathrm{f}}$ and $\varepsilon_{\mathrm{p}}$ of the glassy alloy is $1950 \mathrm{MPa}$ and $0 \%$, respectively. Improvement in strength and ductility was recognized by the precipitation of primary $\beta$-Ti particles and fine dendrites of TiNi compound. Recently, Inoue has already proposed that the glass-forming alloys designed by his empirical component rule $^{1)}$ have unique local atomic configuration in liquid state, such as icosahedral cluster in Zr-based $\mathrm{BMGs}^{25}$ ) or networked trigonal prism in $\mathrm{Fe}-\mathrm{Nb}-\mathrm{B}$ BMGs. ${ }^{26)}$ In addition, Inoue has also pointed out that, if satisfying the component rule, the unique atomic configurations remain the alloys with the composition of low solute content region even beyond glass-forming region. In fact, certain $\mathrm{Mg}$-based crystalline alloys have unique periodic structure, ${ }^{27)}$ and they exhibit high strength and good ductility. High strength and good ductility of the present alloy is now speculated to be its unique atomic configuration. Harding mechanism and deformation behaviors are now under investigation and it will be reported in the near future. In anyway, the newly developed Ti-based alloy exhibits high strength exceeding $2700 \mathrm{MPa}$ and large plastic elongation of $20 \%$, indicating that the alloy is useful material for production of parts of transportation equipment.

\section{Conclusions}

By use of excellent properties such as good imprintability, good soft magnetic properties and high strength with good ductility for BMGs and nonequilibrium crystalline alloy, several industrial products were practically prepared and their performances were evaluated. The results obtained are summarized as follows;

(1) Ni-based BMG microgear with a complicated shape was prepared by injection casting. The microgear exhibits excellent imprintability against mold surface and good fillability into micro Vickers indention. These results indicate that $\mathrm{BMG}$ is useful for production of precision micro parts.

(2) Linear actuator using a set of Fe-based BMG magnetic yokes was practically constructed. The generated Lorentz force for the actuator is evaluated to be $0.4 \mathrm{~N}$. This value is relatively higher than that for the commercial permalloy $(0.2 \mathrm{~N})$, while smaller than that for soft magnetic iron $(0.6 \mathrm{~N})$. These results indicate that the construction of actuator and drive circuit is required to improve by optimum designing for BMGs.

(3) In order to improve the catastrophic fracture manner for BMGs, the method for in-situ precipitation of nano- or micro-sized dendrites by adding elements was employed. As a result, new Ti-based alloy with high strength and good ductility was found. The alloy with a nominal composition of $\mathrm{Ti}_{52} \mathrm{Cu}_{23} \mathrm{Ni}_{11} \mathrm{Mo}_{7} \mathrm{Fe}_{7}$ exhibits high yield strength of $1250 \mathrm{MPa}$, high fracture strength of $2740 \mathrm{MPa}$ and large plastic elongation exceeding $20 \%$.

These results for BMGs are promising for future developments as industrial materials with high performance.

\section{Acknowledgements}

The authors are grateful to M. Ishida, D. Watanabe, A. Urata and $\mathrm{H}$. Soejima for technical assistance and stimulating discussion, and to S. Yamada and T. Fujiwara for magnetic simulations. Funding by the New Energy and Industrial Technology Development Organization under "Processing Technology for Metallic Glasses" of Material Industrial Competitiveness Strengthening Program is gratefully acknowledged.

\section{REFERENCES}

1) A. Inoue: Acta Mater. 48 (2000) 279-306.

2) T. Zhang and A. Inoue: Mater. Trans. 43 (2002) 708-711.

3) N. Nishiyama, M. Ishida, D. Watanabe, K. Amiya, Y. Saotome and A. Inoue: to be submitted.

4) M. Ishida, H. Takeda, D. Watanabe, N. Nishiyama, K. Kita, Y. Saotome and A. Inoue: to be submitted.

5) T. Zhang and A. Inoue: Mater. Trans., JIM 39 (1998) 1230-1237.

6) A. Inoue, T. Zhang and T. Masumoto: Mater. Trans., JIM 31 (1990) 425-428.

7) A. Inoue, W. Zhang and T. Zhang: Mater. Trans. 43 (2002) 1952-1956.

8) S. Pang, T. Zhang, K. Asami and A. Inoue: Mater. Trans. 43 (2002) 1771-1773.

9) C. H. Smith: Applications of Rapidly Solidified Soft Magnetic Alloys, H. H. Liebermann ed., Rapidly Solidified Alloys, (Marcel Dekker, New York, 1993) pp 139.

10) A. Inoue and J. S. Gook: Mater. Trans., JIM 36 (1995) 1180-1183.

11) A. Inoue and J. S. Gook: Mater. Trans., JIM 37 (1996) 32-38.

12) A. Inoue, T. Zhang, H. Koshiba and A. Makino: J. Appl. Phys. 83 (1998) 1967-1974.

13) S. Pang, T. Zhang, K. Asami and A. Inoue: Mater. Trans. 42 (2001) 376-379.

14) B. L. Shen, H. Koshiba, T. Mizushima and A. Inoue: Mater. Trans., JIM 41 (2000) 873-876.

15) S. Yamada, T. Fujiwara and A. Urata: unpublished research.

16) T. Zhang and A. Inoue: Mater. Trans., JIM 39 (1998) 1001-1006.

17) C. L. Ma, N. Nishiyama and A. Inoue: to be submitted. 
18) C. Fan and A. Inoue: Mater. Trans., JIM 40 (1999) 42-51.

19) H. Choi-Yim, R. Busch, U. Köster and W. L. Johnson: Acta Mater. 47 (1999) 2455-2462.

20) R. D. Conner, R. B. Dandliker and W. L. Johnson: Acta Mater. 46 (1998) 6089-6102.

21) C. C. Hays, C. P. Kim and W. L. Johnson: Mater. Sci. A-Struct. 304 (2001) 650-655.

22) G. He, J. Eckert and W. Löser: Acta Mater. 51 (2003) 1621-1631.
23) N. Nishiyama, H. Soejima, K. Amiya and A. Inoue: to be submitted.

24) D. V. Louzguine, H. Kato and A. Inoue: J. Alloys Compd. in press.

25) J. Saida, M. Matsushita and A. Inoue: Mater. Trans. 42 (2001) 11031108 .

26) M. Imafuku, S. Sato, K. Koshiba, E. Matsubara and A. Inoue: Mater. Trans., JIM 41 (2000) 1526-1529.

27) A. Inoue, M. Matsushita, Y. Kawamura, K. Amiya, K. Hayashi and J. Koike: Mater. Trans. 43 (2002) 580-584. 